Gerión. Revista de Historia Antigua

ISSN: 0213-0181

http://dx.doi.org/10.5209/GERI.60298

\title{
Alfareros indígenas de la Hispania Citerior. Un catálogo de sellos con antropónimos vernáculos ${ }^{1}$
}

Ignacio Simón Cornago ${ }^{2}$

Recibido: 18 de noviembre de 2017 / Aceptado: 22 de marzo de 2018

Resumen. El objetivo de este trabajo es recopilar los ejemplos de productores con nombre vernáculo que aparecen en los sellos inscritos sobre cerámica producida en el interior de la provincia de Hispania Citerior. Los sellos aparecen sobre dolia, cerámicas engobadas, tegulae, lateres y terra sigillata.

Palabras clave: Onomástica celtibérica; sellos; cerámica; alfar; Tritium Magallum; Segobriga.

\section{[en] Indigenous potters in Hispania Citerior. A Catalogue of vernacular names in potter stamps}

\begin{abstract}
The aim of this paper is to make a catalogue of the indigenous personal names attested in the potter stamps of the Roman province of Hispania Citerior. The stamps are on dolia, ware ceramics, tegulae, lateres and terra sigillata.
\end{abstract}

Keywords: Celtiberian onomastic; Potter stamps; Pottery; Potter's workshop; Tritium Magallum; Segobriga.

Sumario. 1. Introducción. 2. Problemas para elaborar el catálogo. 3. Catálogo. 3.1. Dolia. 3.2. Cerámicas engobadas. 3.3. Tegulae. 3.4. Ladrillos. 3.5. Terra sigillata hispánica. 4. Conclusiones. 5. Referencias bibliográficas.

Cómo citar: Simón Cornago, I. (2018): Alfareros indígenas de la Hispania Citerior. Un catálogo de sellos con antropónimos vernáculos, en Gerión 36/1, 163-184.

\footnotetext{
1 Este trabajo se incluye en el proyecto de investigación: Hesperia: Lenguas, Epigrafia y Onomástica Paleohispánica (FFI2015-63981-C3-1-P, MINECO/FEDER).

2 Universidad del País Vasco / Euskal Herriko Unibertsitatea UPV/EHU.

E-mail: i.simon@ehu.eus
} 


\section{Introducción}

La conquista romana de la península Ibérica conllevó un gran número de cambios. Si nos centramos en la cultura material y, en concreto, en la cerámica, la llegada de las legiones va acompañada de importaciones itálicas, como la vajilla fina de barniz negro o las ánforas. ${ }^{3}$ Tempranamente, los alfares locales empiezan a producir recipientes que copian o se inspiran en estas novedades. Algunos ejemplos son tan precoces que resulta inevitable pensar en la emigración de ceramistas romanos, es el caso de los morteros que copian la forma de origen campano Emporiae 36,2. ${ }^{4} \mathrm{La}$ sospecha se ve refrendada por los sellos impresos sobre algunos ejemplares, en los que aparecen inscripciones latinas con nombres como Protemus y Fl(accus?), servus de L. Atilius; ${ }^{5}$ acompaña a esta última otra estampilla con un texto ibérico, que se ha interpretado como la traducción del epígrafe latino o como la labor conjunta de un productor procedente de Italia y otro de origen local. ${ }^{6}$ En cualquiera de los casos, este es el periodo (siglos III-I a.C.) en el que los ceramistas indígenas marcan sus producciones con sellos inscritos en signario paleohispánico y lengua ibérica o celtibérica (Fig. 1). ${ }^{7}$ Conocemos un significativo conjunto de estampillas paleohispánicas en el valle medio del Ebro, impresas sobre determinados tipos cerámicos, además de los ya citados mortaria, las formas selladas son las conocidas como tinajas tipo ilduratin y las pesas de telar. Su presencia también es muy informativa sobre la participación de alfareros locales en la puesta en marcha de manufacturas que copian modelos itálicos, como sucede con los citados morteros o, en ámbito mediterráneo, las ánforas Tarraconense $1 \mathrm{o}$ Layetana $1 .{ }^{8}$ Sin embargo, esta documentación desaparece en época de Augusto, cuando decae de forma definitiva el uso de las escrituras paleohispánicas. ${ }^{9}$ No obstante, en el interior peninsular, a diferencia de lo que sucede en las regiones ibéricas, donde la onomástica local desaparece rápidamente, los sellos que se documentan en las manufacturas de época imperial -siempre latinos-sí consignan nombres personales vernáculos, lo que permite vislumbrar la participación de los productores locales o, al menos, de mano de obra indígena en la fabricación de nuevos tipos cerámicos como el material de construcción (tegulae y lateres), cerámicas engobadas, dolia o la terra sigillata. ${ }^{10}$

En definitiva, el objetivo de este trabajo es estudiar las inscripciones y la onomástica que comparece en los sellos sobre cerámica de la Hispania Citerior para arrojar luz sobre la participación de la población local en producciones de nuevo cuño. Tradicionalmente, se ha supuesto que las cerámicas que copian modelos romanos, como la terra sigillata, solo fueron posibles gracias a la inmigración de alfareros que

3 Sobre la cerámica romana puede consultarse la clásica monografía de Beltrán Lloris 1990, con una especial atención por la realidad hispana, así como las actas de los recientes congresos sobre cerámicas hispanorromanas: Bernal - Ribera 2008 y Bernal et alii 2013.

Aguarod Otal 1991, 123-129.

ELRH SC19-20.

MLH IV, K.5.4; Beltrán Lloris 2003; Simón Cornago 2013a, EM2.

Salvat Golobardes 2005; Simón Cornago 2013a.

8 Simón Cornago 2013a, EA4. Sobre las imitaciones pueden consultarse los trabajos reunidos por Roca Roumens - Principal 2007 y Morais et alii 2014.

9 Simón Cornago 2013b.

10 Sobre la onomástica vernácula del interior de Hispania Citerior pueden verse los recientes trabajos de Gorrochategui Churruca et alii 2007, para el valle del Duero; de Navarro Caballero et alii 2011, para el conjunto de la Celtiberia, y de Vallejo Ruiz 2013, para la región astur. 


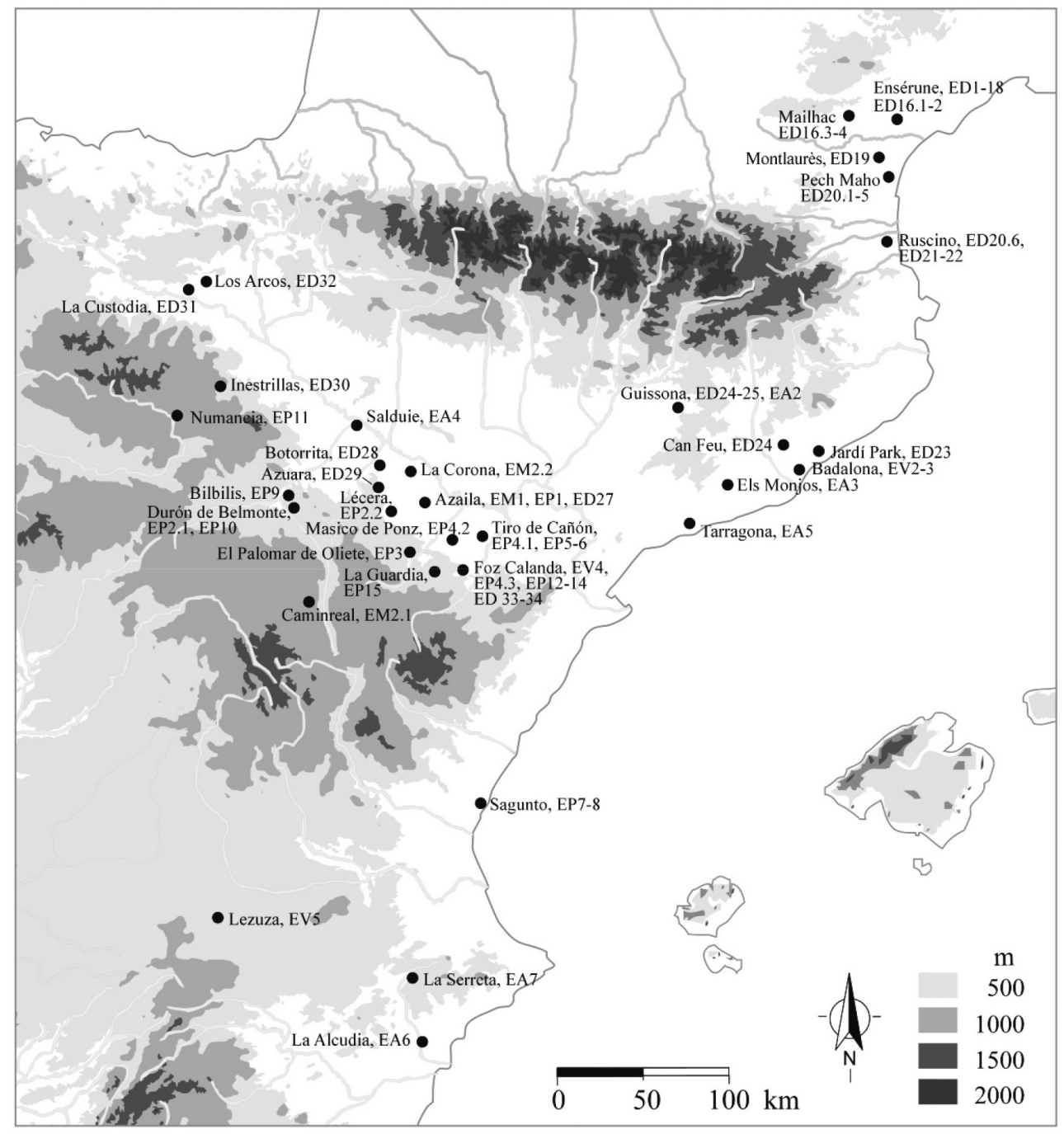

Figura 1. Mapa con los lugares de hallazgo de sellos sobre cerámica con inscripciones ibéricas y celtibéricas (siglos III-I a.C.; Simón Cornago 2013a, 674).

trajeron consigo la nueva tecnología necesaria para elaborar esta vajilla de mesa. Efectivamente, las producciones más precoces -al modo itálico-, que se localizan junto a los campamentos militares de las guerras cántabras (Herrera de Pisuerga y León), presentan sellos de individuos con onomástica completamente latina y con toda probabilidad procedentes de Italia: L. Terentius, Q. Terentius, Capito y C. Licinius Maximus. ${ }^{11}$ En la producción de terra sigillata hispánica se ha señalado la impronta de los modelos gálicos y, por tanto, también la posibilidad del desplazamiento de ceramistas desde la Galia a la península Ibérica. Dicha influencia también se

11 Sobre estos sellos, véase Simón Cornago 2016b, con la bibliografía anterior. 
observa en los llamados alfareros precoces, ${ }^{12}$ cuyas producciones se definen por su afinidad con las sudgálicas, cuya actividad se ubica entre los reinados de Tiberio y Nerón y cuyos productos se distribuyen en el norte de la península, especialmente en el valle del Duero. Firman su producción Asiaticus, Maternus y $M C R$, el nombre de este último se ha podido desarrollar gracias a un sello (M.COR.REBV) encontrado en Coca: Marcus Cornelius Reburrus, que arroja un cognomen indígena típicamente hispano, por lo que puede deducirse un origen local para este último personaje. ${ }^{13} \mathrm{El}$ objetivo de este trabajo ha sido localizar otros personajes como este M. Cornelius Reburrus, un individuo de origen local implicado en la producción de una vajilla típicamente romana.

Tal y como sucede en todos los periodos en los que se documentan las estampillas sobre cerámica, estas solo aparecen sobre determinados tipos y no sobre otros. En el caso que nos ocupa solo se sella la vajilla fina de mesa (terra sigillata), pesas de telar, recipientes de cocina, dolia, materiales de construcción (tejas y ladrillos) y determinadas formas de cerámica engobada, mientras que no se atestiguan sellos en otras como la llamada cerámica de tradición indígena. ${ }^{14}$ Solo en una parte de ellos aparecen nombres de individuos de origen local, que siempre son minoría frente a los personajes de onomástica latina. En el catálogo están organizados por categorías cerámicas $\mathrm{y}$, dentro de cada una de ellas, el material se ordena por el lugar de hallazgo, excepto en el caso de la terra sigillata producida en Tricio, ya que no siempre se conoce de qué alfar concreto del Najerilla procede cada marca.

\section{Problemas para elaborar el catálogo}

En este artículo pretendemos compilar el conjunto de sellos que procede de Hispania Citerior y en los que se recogen antropónimos indígenas, durante una época concreta: el Alto Imperio (siglos I y II d.C.). El objetivo no es sencillo, pues no es habitual que el instrumentum inscriptum se incluya en los corpora epigráficos, mientras que en muchos trabajos arqueológicos solo se ofrece la transcripción de los sellos, sin una lectura propiamente dicha, que en este tipo de inscripciones implica el desarrollo -no siempre evidente- de las omnipresentes abreviaturas, y sin una interpretación del texto.

Los problemas de lectura y, en algunos casos, el hecho de que la pieza en cuestión no se conserve dificultan aún más el trabajo. Puede ejemplificar bien el primero de los problemas un sello proveniente de Turiaso (Tarazona, Zaragoza), pues la corrección de la lectura que ofrecía su editora invita a excluirlo de nuestro catálogo. El sello está impreso sobre un cuenco de cerámica engobada, que imita la forma Dragendorff 27 de la sigillata y que fue recuperado de forma casual en Santa Ana, en las cercanías de Tarazona. No obstante, por sus características formales se ha propuesto que provenga de un alfar situado en esta ciudad, concretamente en la Calle del Cara-

\footnotetext{
Véase en último término Romero Carnicero et alii 2016.

Blanco García - Juan Tovar 1996, 148-151, fig. 1; OPEL IV, 24; Vallejo Ruiz 2004, 384-390, y 2016, 399-405.

Sí se documentan sobre este tipo de cerámica algunos tituli picti (Lorrio Alvarado - Pérez Blasco 2015); en la reciente síntesis que Blanco García 2017 ha dedicado a la cerámica común de fabricación local -tanto de cocina como de mesa- recuperada en la Meseta, los sellos brillan por su ausencia. Por su parte, en las estampillas sobre la llamada cerámica de engobe rojo lucense solo se recogen nombres latinos; véase, al respecto, el reciente catálogo publicado por Bartolomé Abraira 2015.
} 


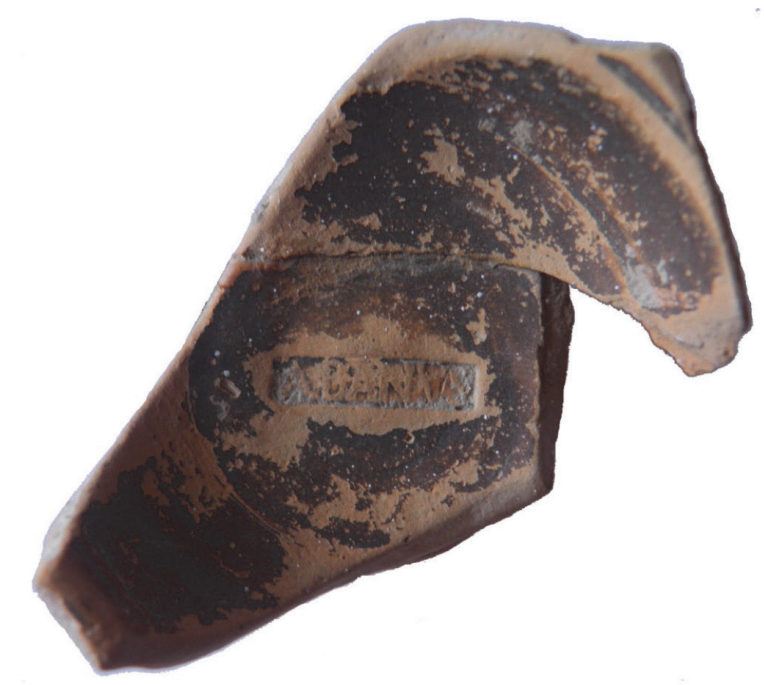

Figura 2. Sello de Albanus sobre una cerámica engobada de Tarazona, Zaragoza (fotografía J. Lavena).

col, en la que fue exhumada una gran acumulación de cerámica interpretada como un testar de época altoimperial. El taller producía lucernas, cerámica engobada (vasos de paredes finas, ollas, cuencos, botellas, jarras y cantimploras), terracotas y cerámica común (morteros, lebrillos, botellas, tapaderas y cuencos). ${ }^{15}$

La marca está impresa en el fondo interno del cuenco, tal y como sucede en la TSH, cuyos alfareros también sellan habitualmente esta forma (Dragendorff 27). La cartela es rectangular y de extremos rectos $(0,4 \times 1,8 \mathrm{~cm})$ y el texto que delimita es ABANVS. ${ }^{16}$ C. Aguarod ${ }^{17}$ lo identifica como un antropónimo indígena indoeuropeo (Abanus/-a), que cuenta con varios paralelos en la epigrafía de la península Ibérica: Munigalici Abani Bouti f..$^{18}$ y Calpurnia Abana Aeboso $(c a) .{ }^{19}$ Además, en las excavaciones efectuadas en el solar del colegio Joaquín Costa, también en Tarazona, apareció el mismo nombre personal (Abani), en este caso grabado post cocturam sobre una TSH (Ritterling 8). ${ }^{20}$ Sin embargo, J. A. Mínguez ${ }^{21}$ lee 'AL'BANVS, con un nexo al y, por tanto, el resultado es un cognomen latino y no indígena, bien documentado en la península Ibérica. ${ }^{22}$ La corrección propuesta por Mínguez es acertada, tal y como hemos podido comprobar sobre una fotografía de la pieza que nos ha facilitado su actual propietario y, por tanto, ha quedado fuera del catálogo (Fig. 2). ${ }^{23}$

\footnotetext{
15 Aguarod Otal 1984.

16 Aguarod Otal 1984, 98, nº 59, fig. 16, lám. 1.1. En el mismo alfar se documentan varios sellos, todos incompletos, sobre lucernas (Amaré Tafalla et alii 1983, 108).

7 Aguarod Otal 1984, 98-100.

18 CIL II 5717, de Valdoré (Crémenes, León).

19 CIL II 2527 (Orense). Véase también Vallejo Ruiz 2004, 158-160, y 2016, 239.

20 Beltrán Lloris 2004, 256, fig. 107.7 (=AE 2004, 791a=HEp 13, 2003-2004, 762).

21 Mínguez Morales 2008b, 431. Se utilizan las comillas antes y después de las letras que están unidas en nexo.

22 Abascal Palazón 1994, 264.

23 Agradecemos al Sr. J. Lavena que nos haya proporcionado fotografías de esta pieza.
} 
En otros casos el texto nos ofrece un hapax, como sucede en un sello sobre un dolium recuperado en la villa de las Musas de Arellano (Navarra), en el que se lee BIRICCO (Fig. 3). ${ }^{24}$ No tiene paralelos ni en la onomástica latina, ni en la griega ni tampoco en la indígena, aunque el final recuerda al sufijo -ko-, característico de los nombres familiares celtibéricos, si bien la geminación de $\mathrm{C}$ en este tipo de denominaciones es insólita. ${ }^{25} \mathrm{La}$ falta de paralelos dificulta enormemente su clasificación lingüística, sin excluir que el texto deba segmentarse y reúna varias abreviaturas, que en cualquier caso resultan completamente opacas.

También es incierta la clasificación lingüística de Verdullus, el cognomen de Gaius Valerius Verdullus, célebre por su producción de vasos de paredes finas caracterizada por unas singulares decoraciones en relieve ${ }^{26}$ habitualmente acompañadas por rótulos de diferente carácter. Su alfar se localiza en La Maja (Pradejón, La Rioja), próximo a Calahorra, ${ }^{27}$ y su actividad se concentra en la primera mitad del siglo I d.C. El personaje consigna en sus vasos sus tria nomina y su origen calagurritano ${ }^{28}$ pero tiene un cognomen de clasificación lingüística incierta, dado que apenas cuenta con paralelos. Se ha afirmado su carácter indígena, ${ }^{29}$ pero se documenta como nomen de dos mujeres en una inscripción de Cemenelum (Cimiez, Francia): D. M. / Verduliae Cupitae / Verdulia Victori/a alumna patronae be/ne merenti posuit,${ }^{30}$ por lo que no se puede excluir que fuese un nombre latino o incluso galo. ${ }^{31}$

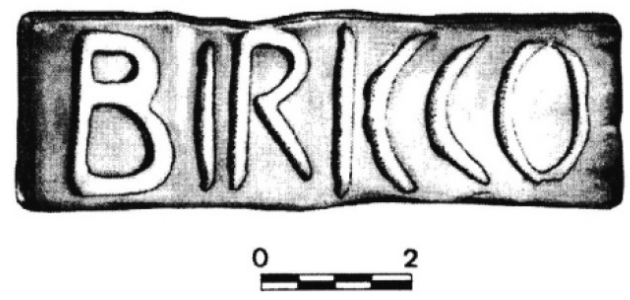

Figura 3. Sello BIRICCO, sobre un dolium de la villa de las Musas de Arellano, Navarra (Mezquíriz Irujo 2003, 103).

\footnotetext{
Mezquíriz Irujo 1993-1994, nº 67.

Villar - Jordán Cólera 2001.

Véase Mínguez Morales 2008a.

27 Sobre la posibilidad de que también emplease un alfar localizado en Arenzana de Arriba, véase Sáenz Preciado 1994, 90-92.

28 Espinosa Ruiz - Castillo Pascual 1995-1997, 109, nº 2 (de donde HEp 7, 1997, 583). En González Blanco et alii 1996, 58, nº VIII.3 (de donde HEp 7, 1997, 589) y Beltrán Lloris 1984 también se menciona el municipio de Calagurris.

29 Sáenz Preciado 1994, 90. Beltrán Lloris 1984, 133, lo compara con el etnónimo Varduli.

30 Laguerre $1975, n^{\circ} 123$.

31 Cf. Schmidt 1957, 290-293.
} 


\section{Catálogo}

\subsection{Dolia}

\section{Vareia}

Se trata de un sello impreso sobre dos fragmentos de dolia recuperados en Varea (La Rioja). ${ }^{32}$ Emplean una cartela rectangular $(2 \times 6,8 \mathrm{~cm})$ que recoge el siguiente texto: PO 'MPE' · COLISI (Fig. 4). Es decir: Po 'mpe'(i) · Colisi, una fórmula onomástica compuesta por nomen y cognomen, separados mediante una interpunción triangular. ${ }^{33}$ El primero es un gentilicio bien documentado en Hispania ${ }^{34}$ y el segundo es un antropónimo indígena, tal y como señala R. A. Luezas, ${ }^{35}$ pues cuenta con un paralelo exacto en un epígrafe de Muro de Ágreda (Soria), en el que aparece un individuo de origen calagurritano llamado C. Caecilius Colisi $f .{ }^{36}$ La raíz de este antropónimo, además, se documenta en otros nombres personales vernáculos. ${ }^{37}$

Uno de los dos sellos procede de un contexto arqueológico datado entre la segunda mitad del siglo II y comienzos del III d.C., lo que marca la fecha ante quem para estas estampillas. ${ }^{38}$

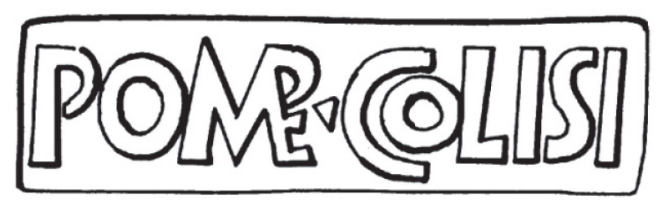

Figura 4. Sello de Pompeius Colis(i)us, sobre dolium de Vareia, La Rioja (Espinosa Ruiz 1994, 188, fig. 52b).

\subsection{Cerámicas engobadas}

\section{Calahorra}

Sello impreso en el fondo interior de un plato recuperado en el solar de La Clínica en Calahorra (La Rioja) y rodeado por un círculo, presenta un texto dispuesto en una única línea y una cartela rectangular con extremos bífidos $(0,35$ x 3,1 cm). Su editor lo clasificó como un plato de $\mathrm{TSH},{ }^{39}$ pero en realidad es una imitación local de las denominadas cerámicas de engobe interno rojo-pompeyano (Fig. 5). ${ }^{40}$

\footnotetext{
32 Sobre este tipo de contenedores, además del trabajo de Luezas Pascual 1998 sobre los sellos, véase ahora también Salido Domínguez 2017. Sobre la ciudad romana de Vareia: TIR K-30, 236.

33 Espinosa Ruiz 1994, 188, fig. 52a-b. Luezas Pascual 1998, nº 11, por contra, desarrolla el texto en nominativo: Pompe(ius) Colisi(us).

34 Abascal Palazón 1994, 198-201.

35 Luezas Pascual 1998, 213-214.

36 ERPS 78.

37 Vallejo Ruiz 2004, 289, y 2016, 332.

38 Espinosa Ruiz 1994, 188.

39 ERR, ID11. Sobre el municipio de Calagurris: TIR K-30, 75-76.

40 Su correcta clasificación tipológica en Luezas Pascual 1997 y 2002, 173-176.
} 

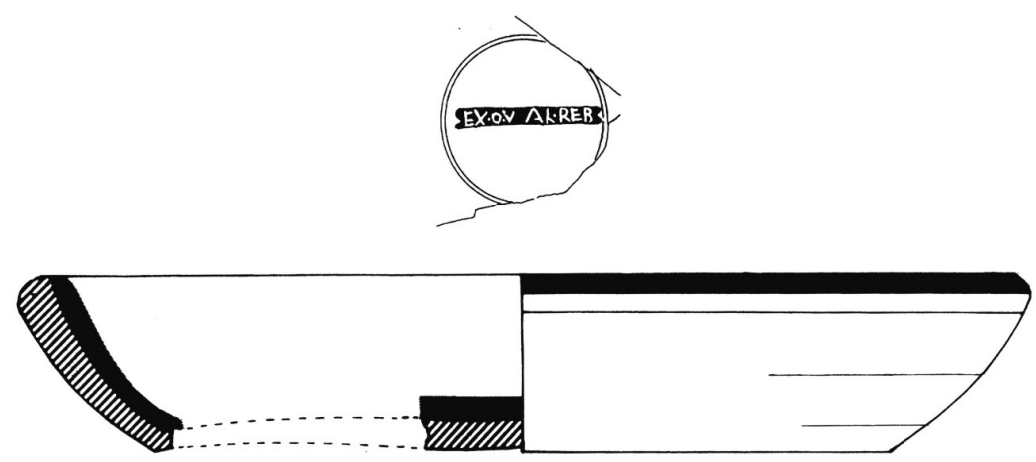

Figura 5. Sello $E X \cdot O \cdot V A L \cdot R E B$, sobre cerámica engobada de Calahorra, La Rioja (según Luezas Pascual 1997, fig. 1).

La lectura e interpretación del epígrafe propuesta por U. Espinosa ${ }^{41}$ es completamente plausible: ex $\cdot o(f f i c i n a) \cdot V a l($ eri) $\cdot$ Reb(urri), pues Valerius es el segundo gentilicio romano más común en Hispania ${ }^{42}$ y no hay cognomen latino que presente el inicio $R e b$-, mientras que entre los antropónimos indígenas hay varios candidatos, de los que el más común precisamente es Reburrus. ${ }^{43}$

R. A. Luezas ${ }^{44}$ señala acertadamente la similitud de este sello con los empleados en la TSH, ya que el diseño de la cartela también se emplea en estos últimos y el término officina es igualmente omnipresente. ${ }^{45}$ Esta misma autora plantea su posible relación con los productores de sigillata hispánica Val(erius?) Reburrinus y Reburrus, sobre los que volveremos más adelante. Si, efectivamente, el sello que nos ocupa es de uno de estos dos últimos ceramistas citados, produciría tanto TSH como platos de imitación de engobe rojo pompeyano. ${ }^{46}$ Lamentablemente no conocemos la cronología precisa de la actividad de ninguno de ellos, pero de ser cierto este lazo, parece más plausible identificar al productor del plato calagurritano con el primero de los ceramistas de sigillata, pues comparten el mismo nomen, en tal caso el desarrollo de nuestro sello debería ser ex $\cdot o(f f i c i n a) \cdot \operatorname{Val}($ eri?) $\cdot$ Reb(urrini).

\subsection{Tegulae}

Segobriga

En las excavaciones realizadas en esta ciudad se ha descubierto una serie de 46 tegulae con marcas de alfarero, entre las que se documentan los nombres de siete productores, tres de ellos indígenas. ${ }^{47}$

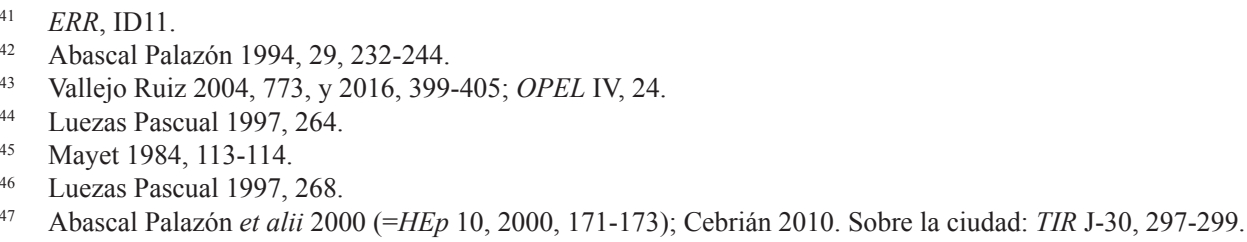




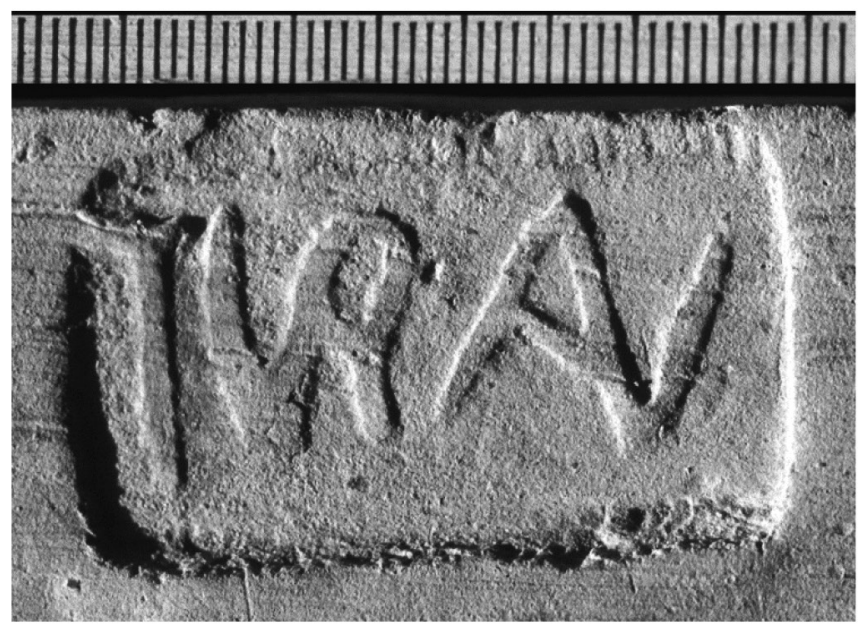

Figura 6. Sello de Turanus, sobre tegulae de Segobriga, Cuenca (fotografía de Abascal et alii 2001, lám. I.1, amablemente cedida por R. Cebrián).

Turanus: conocido por las firmas $T$ 'VR' ' $A N$ ' y $T$ ' $V R$ ' ' $A N I$ ' (Fig. 6), atestiguadas en cuarenta improntas, para cuya ejecución se han empleado varios signacula diferentes. Todas ellas en cartelas rectangulares $(2,5 \times 4,4 \mathrm{~cm})$, en ocasiones acompañadas de marcas anepígrafas tetralobuladas. El formato de las tegulae impresas es de $58 \times 43 \mathrm{~cm}(2 \times 1,5$ pies $) .{ }^{48}$ El antropónimo Turanus, que aparece en estas marcas en genitivo, es un nombre vernáculo bien documentado en el área lingüística indoeuropea de Hispania y, aunque se considera característico de la Lusitania, en el tercer bronce de Botorrita se consigna por dos veces el nombre familiar turanikum (K.1.3, II-4 y IV-38). ${ }^{49}$

Retucenus: conocido por la firma RETVC - IILOCI, de lectura comprometida. Para separar los dos términos que componen el epígrafe se emplea un punto a media altura de la caja de escritura. Se atestigua en un grupo de improntas de cartela rectangular y ángulos redondeados $(2,3 \times 7,8 \mathrm{~cm})$, incluso sus editores no excluyen que adopte la forma estilizada de una planta pedis. Se fechan a mediados del siglo I d.C. y el texto es: Retuc(eni) - Eloci. El primero lo identifican como un antropónimo indígena y el segundo como un nombre familiar (Retucenus Elocum). ${ }^{50}$ Sin embargo, sorprende que se emplee el genitivo singular, por ello no sería imposible considerarlo como un patronímico. ${ }^{51}$ Retucenos/Rectugenus es un antropónimo bien documentado tanto en las inscripciones celtibéricas como en la posterior epigrafía latina. ${ }^{52}$ Las variantes que se conocen de este nombre están bien ejemplificadas en estos sellos, pues el mismo productor emplea en sus firmas tres de ellas: Retuc(enus), Retugen(us)

48 Abascal Palazón et alii 2000, 188-191 (=HEp 10, 2000, 171); Cebrián 2010, 169-176.

49 Untermann 1996, 161; Vallejo Ruiz 2004, 439, y 2016, 439.

50 Abascal et alii 2000, 191-192 (=HEp 10, 2000, 172a); Cebrián 2010, 176-177. Luján 2016, 246, también estima probable que sea un nombre referente a una unidad familiar.

51 Sobre la expresión de los nombres familiares celtibéricos en genitivo singular, véase Gorrochategui Churruca 2011, 207-211.

52 Untermann 1996, 151. 
y Rect(ugenus o -ucenus). Se trata de un nombre compuesto por recto y geno, que podría traducirse como "hijo del derecho". ${ }^{53}$ Por su parte, Eloci (genitivo singular) encuentra su mejor paralelo en el nombre familiar elokum, registrado en el tercer bronce de Botorrita. ${ }^{54}$

Se conocen, además de esta, otras firmas de este mismo productor. El texto Retugen $(i) \cdot E[$ loci?] se preserva sobre dos improntas rectangulares que se conservan de forma fragmentaria: RETVGEN $\cdot E[-$ - - y $R E T V[-$ - - ], para las que parece haberse empleado signacula diferentes. Se trata del mismo individuo que aparece en los sellos anteriores, aunque en esta firma su nombre aparece más completo (RETVGEN frente a RETVC) y está escrito con $\mathrm{G}$ y no con $\mathrm{C}$. Los indicios cronológicos apuntan a una datación similar a la de las estampillas anteriores. ${ }^{55}$ Se conocen dos marcas más que también se relacionan con ellas, pero solo se conserva la parte final del texto: [- - - ]LOCI y [- - -]CT $\cdot E L O$, que sus editores proponen interpretar como [- - E?]loci y [Re]ct(ugeni?) · Elo(ci?), respectivamente. ${ }^{56}$

Antirus: se conoce por una firma de la que se conservan dos improntas, que lucen el texto $A N / T I R$. Está escrito de izquierda a derecha, dispuesto en dos líneas y enmarcado por una cartela cuadrada de esquinas redondeadas $(2,6 \times 2,5 \mathrm{~cm})$. Su fecha de amortización se sitúa a finales del siglo I d.C. Se puede reconocer el nombre personal Antirus, que sus editores desarrollan en genitivo An/tir(i). ${ }^{57}$ Lo comparan con antiros, documentado en una tésera de hospitalidad celtibérica: otoni · a / ntir (o ntor) / os / biltire / i · kor / tika; ${ }^{58}$ y también con Antirus de una inscripción de Numão (Guarda). ${ }^{59}$

La producción de tegulae por parte de estos alfareros y de otros atestiguados en Segobriga depende de la demanda de la ciudad, que debió ser especialmente acusada durante el reinado de Augusto con la monumentalización y construcción de los más importantes edificios públicos, con los que se relacionan buena parte de estos sellos, especialmente los de Turanus (atestiguado principalmente en el área del foro y edificios adyacentes), productor del que se conocen un mayor número de marcas y que estuvo activo desde época augustea. ${ }^{60}$

\section{El Alba, Villalazán (Zamora)}

Sobre tegulae se documentan los dos siguientes sellos: TVRII y TVRII OF, ambos reconocibles como firmas de un mismo productor, ya que recogen el mismo nombre y provienen de un mismo lugar. ${ }^{61}$ De la primera variante se conocen dos improntas y de la segunda tan solo una, todas ellas recuperadas en Villalazán. ${ }^{62}$ Turius es un nom-

\footnotetext{
53 Albertos Firmat 1966, 192; sobre este nombre compuesto, véase también Vallejo Ruiz 2005, 117-119 y 123; 2016, 405-406.

$54 \quad M L H$ IV, K.1.3 III-28.

55 Abascal Palazón et alii 2000, 192-193 (=HEp 10, 2000, 172b).

56 Abascal Palazón et alii 2000, 193-194 (=HEp 10, 2000, 172c-d).

57 Abascal Palazón et alii 2000, 193-194 (=HEp 10, 2000, 173).

8 MLH IV, K.0.10.

59 Coixão - Encarnação 2001, 202-203 (=AE 2001, 1162=HEp 11, 2001, 675).

60 Cebrián 2010, 180.

${ }_{61}$ El yacimiento tiene rango urbano y se identifica con Arbocala o Albocela (véase Lorenzo Morán et alii 1996; Núñez - Curchin 2007, 432-435).

${ }^{62}$ Martín Valls - Delibes de Castro 1979, no 18 y 19. El primero de ellos fue leído de forma incorrecta por Sevillano Carvajal 1967, 154; también están compilados por Mañanes Pérez 1983, Zamora nº 18 y 19.
} 
bre indígena, aunque con un homónimo latino (Turius es un gentilicio romano) ${ }^{63}$ pero parecen tener una distribución claramente diferenciada en la península Ibérica: los primeros se concentran en Lusitania y los segundos en Gadir. ${ }^{64}$

\section{Santa Cristina de la Polvorosa, Villafáfila y Manganeses (Zamora)}

En un sello documentado sobre tegulae recuperadas en Santa Cristina de la Polvorosa y Villafáfila (Zamora) aparece el nombre indígena Matugenus: Matugeni fa (?) / Valeri Tauri of(ficina). ${ }^{65}$ Se trata de un nombre personal compuesto: Matu("mat-u, "oso") y "genos ("nacido de"), bien documentado en Hispania y especialmente en la Meseta norte. ${ }^{66}$ Un sello de este personaje también se ha recuperado en el alfar de La Corona/El Pesadero, en Manganeses (Zamora), junto a otros de Cepalio, un individuo de nombre griego y también dependiente de Valerius Taurus, del que se conocen dos firmas: Cepali(o) of(ficinae) / Valeri(i) Tauri ${ }^{67}$ y Valeri Tauri Cepalionis. ${ }^{68}$

Aquis Querquennis (Baños de Bande, Lugo ${ }^{69}$

En este campamento militar se ha recuperado una serie de sellos sobre tegulae en los que aparecen los nombres: Rufus, Saturninus y Marcius, el primero de los cuales no es exclusivo de este yacimiento sino que se conoce en otros de la comarca. Interesan aquí los sellos con el texto: CLOVT (Fig. 7). No existe ningún cognomen latino con tal inicio y, sin embargo, casa perfectamente con Cloutius, como señala A. Rodríguez Colmenero, ${ }^{70}$ un nombre personal indígena bien atestiguado en Hispania y especialmente en el bajo Esla. ${ }^{71}$

\subsection{Ladrillos}

\section{León}

En la ciudad se han recuperado tegulae y lateres con sellos que portan el nombre de la legio VII y sus diferentes epítetos. ${ }^{72}$ Pero en algunos ejemplares, como los recuperados en la necrópolis tardoantigua de Vegazana, acompañan al nombre de la legión -leg(io) VII Ge(mina) - antropónimos abreviados: LEG VII GE LVCI, LEG VII GE MAS, LEG VII GE PRI, LEG VII GE SEV y LEG VII GE REB. ${ }^{73}$ La última de ellas

\footnotetext{
63 Solin - Salomies 1994, 192.

64 Vallejo Ruiz 2004, 441-442, y 2016, 440.

65 Abásolo - García 1999, 314.

66 Vallejo Ruiz 2004, 351-354; 2005, 117-119, 121, y 2016, 377. Matugenus también está atestiguado en la Galia: Schmidt 1957, 240, Forier 2001, 486-487, donde hay varios productores de terra sigillata con este nombre (Hartley - Dickinson 2010 VI, 28-32).

67 Abásolo - García Rozas 1999, 314, y 2006, 148; Misiego Tejada et alii 2013, 360-363.

68 Abásolo - García Rozas 2006, 148; Misiego Tejada et alii 2013, 360-363.

69 TIR K-29, 23.

70 Rodríguez Colmenero 2006, 163, fig. 23.

71 Vallejo Ruiz 2004, 283-285, y 2016, 329-331.

72 Véase una reciente revisión en Morillo - Salido 2013, 289-305.

73 Liz Guiral - Amaré Tafalla 1993, 56, figs. 14-16. Algunas improntas de este sello se conocían previamente: $C I L$ II 2667 y 6252o. También fueron compiladas por Gómez Moreno 1925, 47.
} 

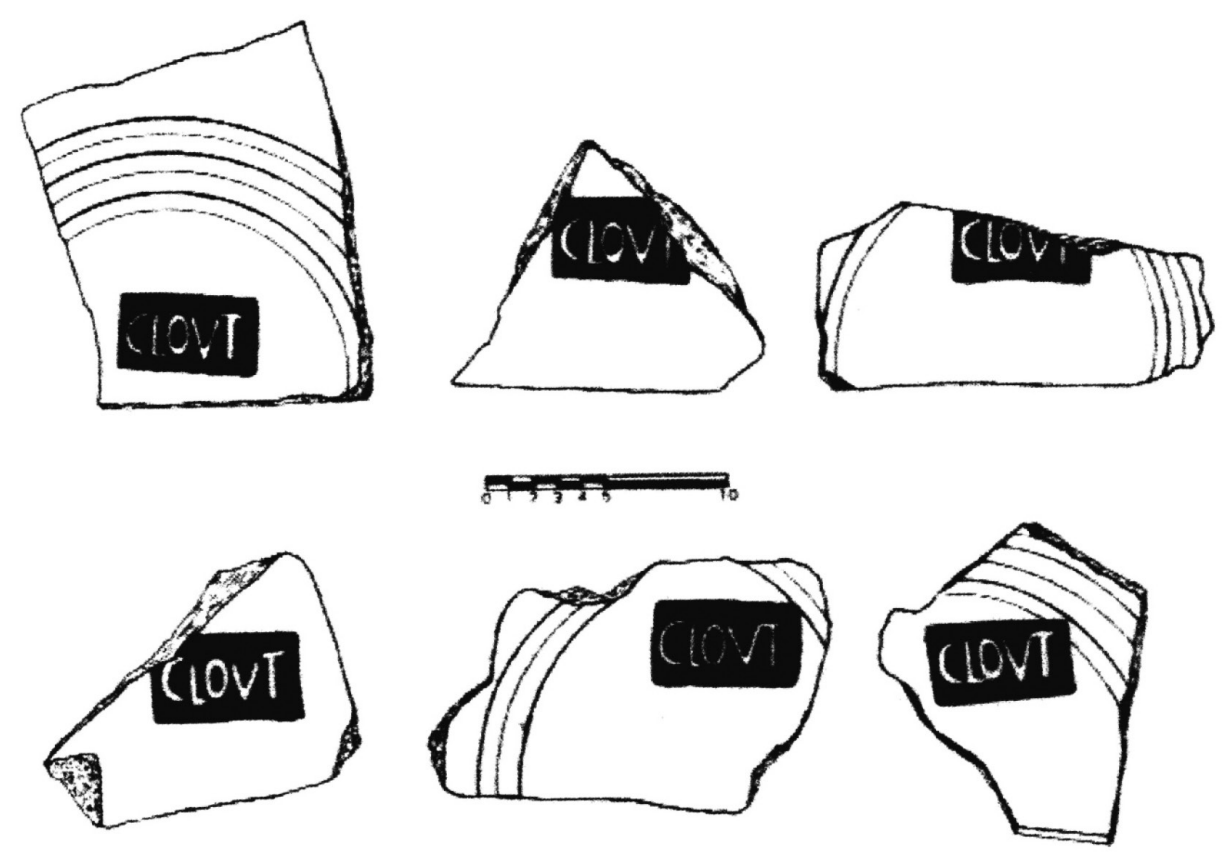

Figura 7. Sellos de Cloutius, sobre tegulae, de Baños de Bande, Lugo (Rodríguez Colmenero 2006, 165, fig. 23).

está impresa sobre semitambores de columna (testae) ${ }^{74}$ y es la que aquí interesa, pues es plausible desarrollar los nombres indígenas Reburrus/Reburrinus como ya propuso E. Hübner. ${ }^{75}$ Según P. Le Roux, ${ }^{76}$ las denominaciones de estos personajes [ $L u c i$, Mas(culi?), Pri(mi) y $\operatorname{Sev}($ eri?)] induce a pensar que fuesen esclavos, aunque en nuestro caso también pudiera ser un peregrinus.

\section{Astorga}

Sobre tres ladrillos recuperados en las obras de ensanche del Paseo de la muralla en Astorga, ${ }^{77}$ junto al Seminario, hay impresa una marca rectangular $(10 \times 7 \mathrm{~cm})$ con el siguiente texto: EX OF / PROTI VAC/AIAE. ${ }^{78}$ Precede al nombre del productor la fórmula ex of(ficina). El segundo nombre es indígena, que comparte la raíz ${ }^{*}$ wak con otros antropónimos de la Hispania indoeuropea. ${ }^{79}$

Protus / Proto / Protis son nombres griegos atestiguados en Hispania. ${ }^{80}$ El último de ellos lo porta la mujer de un liberto enterrada en la propia Astorga. ${ }^{81}$ Protius tam-

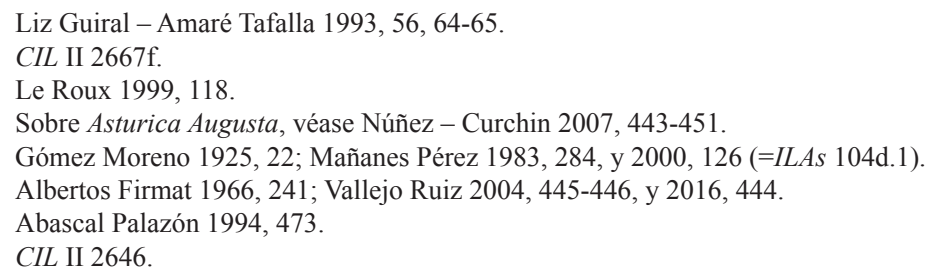


bién está atestiguado como nomen, ${ }^{82}$ pero parece poco común y de hecho no está documentado en Hispania. Es difícil interpretar el texto puesto que parece recoger dos idiónimos, ambos en genitivo, por lo que el primero -que por ser un nombre griego puede considerarse que corresponde a un esclavo- sería siervo de Vacaia.

\subsection{Terra sigillata hispánica}

En el valle del Najerilla, territorio de la ciudad de Tritium Magallum, se establece el principal complejo productor de terra sigillata hispánica. ${ }^{83}$ Se conocen más de trescientos ceramistas que en su mayoría portan nombres latinos, ${ }^{84}$ pero también hay un pequeño grupo de antropónimos vernáculos. Recientemente hemos estudiado la onomástica de este amplio conjunto de sellos y hemos establecido una nómina mucho más reducida de nombres indígenas de la defendida por F. Mayet: ${ }^{85}$ Cantaber, Reburrus, Atto, Val(erius?) Reburrinus y Titus Aio.$^{86}$ Aunque es cierto que existen algunos nombres homófonos (Attius, Titius, Segius y Annius), que pudieran clasificarse tanto como latinos como indígenas, así como otro pequeño grupo de nombres susceptibles de interpretarse como Decknamen, especialmente los llamados cognomina de parentesco, como Maternus y Paternus, muy comunes en la epigrafía de la Meseta norte..$^{87}$

Cantaber es un productor del que se conservan hasta catorce firmas diferentes. La más completa es: Cantabri $\cdot$ off(f)ic(ina) ${ }^{88}$ Es un nombre personal derivado del de un populus, Cantabri ${ }^{89}$ y está ampliamente documentado en la península Ibérica. Por su parte, Reburrus es un nombre típicamente hispano, del que ya hemos hablado previamente. De este productor se conocen tres sellos, uno completo y dos fragmentarios. El único que se preserva íntegro fue descubierto en León: OFREBVRRI ${ }^{90}$ fácil de desarrollar como of(ficina) Reburri.

Del tercero de los productores solo se conserva un sello in planta pedis exhumado en La Cerezada (Arenzana de Arriba): VAL $R I I B V R I N .{ }^{91}$ Su editora propone desarrollar el texto como Valerius Reburrinus. Valerius parece el desarrollo más plausible del gentilicio, ya que se trata de uno de los nomina latinos más populares en Hispania ${ }^{92} \mathrm{y}$, además, lo portan otros alfareros de Tricio. ${ }^{93} \mathrm{El}$ cognomen de este productor es el nombre personal indígena Reburrinus.$^{94}$ Lo más probable, a juzgar por lo que sucede en otras estampillas de Tricio, es que deban de desarrollarse en genitivo: Val(erii?) Rebur(r)in(i).

El cuarto productor de terra sigillata hispánica solo se conoce por una marca intradecorativa, cuyo texto se dispone circularmente. Se documentan seis ejemplares

82 Solin - Salomies 1994, 150.

83 La monografía clásica sobre este conjunto alfarero es la de Garabito Gómez 1978.

84 La recopilación más completa y actualizada en Sáenz Preciado - Sáenz Preciado 1999.

85 Mayet 1984.

86 Simón Cornago 2016a

87 Abascal Palazón 1984.

88 Mayet 1984, nº 119-129; Mezquíriz Irujo 1985, n 53; Beltrán Lloris 1990, 114; Sáenz Preciado - Sáenz Preciado $1999,97$.

89 Véase García Alonso 2006, 80-81.

90 García Marcos 1990, nº 25, fig. 3, n 25; Sáenz Preciado - Sáenz Preciado 1999, 121.

91 Sáenz Preciado 1994, 92, lám. 8, nº 30; Sáenz Preciado - Sáenz Preciado 1999, 133.

92 Abascal Palazón 1994, 29.

93 [O]f(ficina) Cai(i) Valer(ii), [O]FCAIVALER (Mayet 1984, n 113); y Valeri(i), VALERI (Sáenz Preciado Sáenz Preciado 1999, 129).

94 Abascal Palazón 1994, 480; Vallejo Ruiz 2004, 387-388, y 2016, 400. 


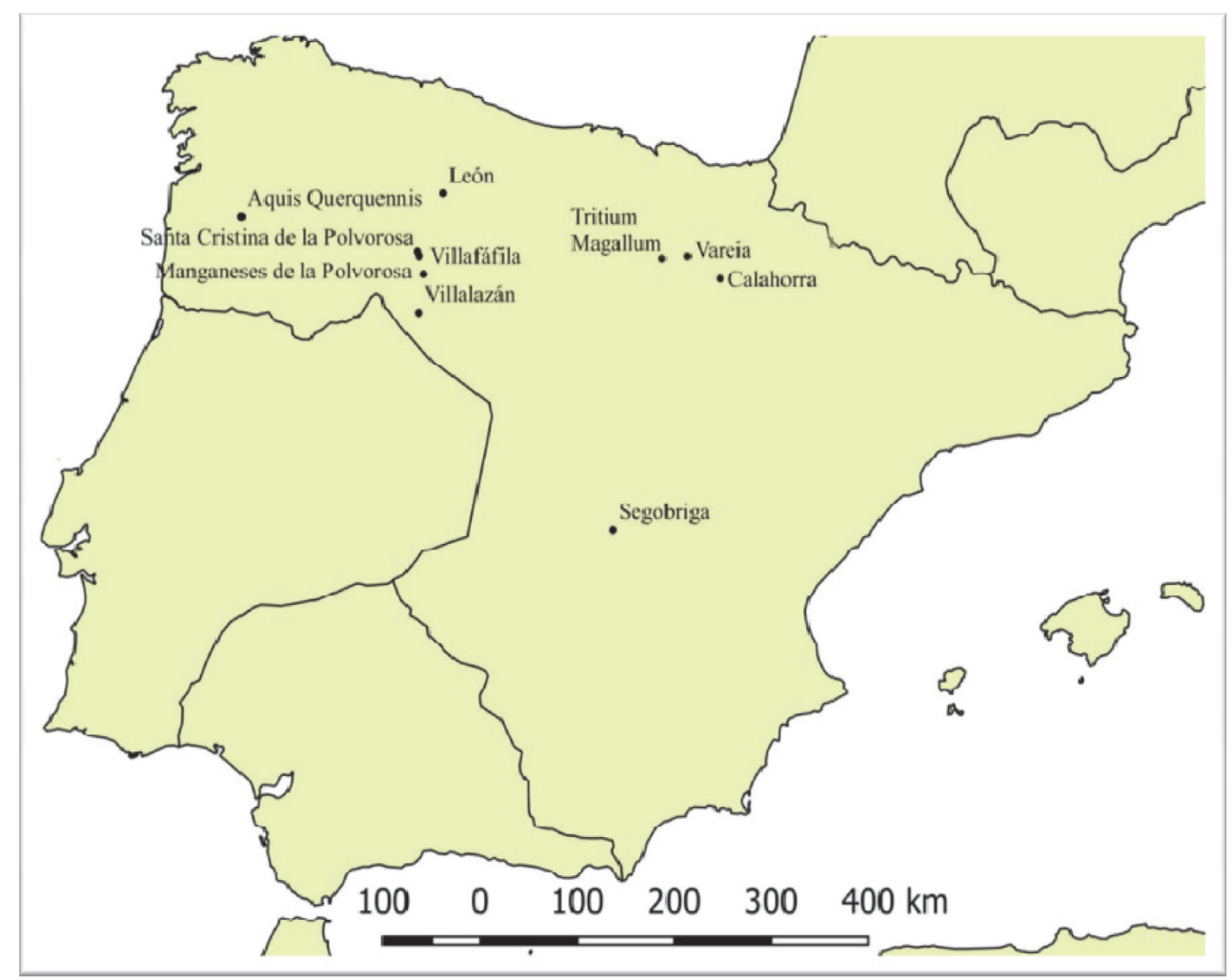

Figura 8. Mapa con los lugares citados en el catálogo.

de esta firma, aunque únicamente el recuperado en Numancia se preserva íntegro. Esta última pieza es la que permitió determinar definitivamente la lectura del epígrafe como Titi $\cdot$ Sangeni $\cdot{ }^{95}$ Sangenus es un nombre indígena documentado en varias inscripciones latinas hispanas: Valerius Sangeni f. (Vxama) ${ }^{96}$ Elgiamo Sangen[us] (Ávila) y [S]angenu [s] Conce [l]ti $f$. (Ibahernando, Cáceres). ${ }^{97}$ Lo más plausible es interpretar el primer término como el nomen Titius. ${ }^{98}$

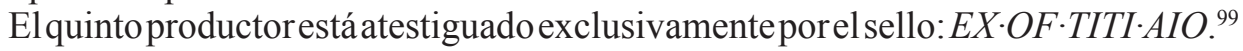
Se ha atribuido a Titius Aio, pero al estar precedido de la fórmula ex officina parece preferible desarrollar el nombre en genitivo: Titi(i) Aio(nis). Titius está documentado como gentilicio y Aio, que aquí parece funcionar como cognomen, es un nombre indígena bien atestiguado y característico de la Celtiberia. ${ }^{100}$

\footnotetext{
Romero Carnicero 1985, nº 708, 279-280, fig. 68, 1986.

CIL II 2817.

Vallejo Ruiz 2004, 394, y 2016, 408.

Solin - Salomies 1994, 187.

99 Mayet 1984, no 649; Mezquíriz Irujo 1985, nº 296; Beltrán Lloris 1990, 116; Sáenz Preciado - Sáenz Preciado $1999,128$.

100 Untermann 1996, 123, mapa 2.2.2; Vallejo Ruiz 2004, 111-112, y 2016, 248.
} 


\section{Conclusiones}

Únicamente son quince los productores con nombre vernáculo, lo que representa una pequeña parte en un conjunto de sellos en el que predomina ampliamente la onomástica latina, como ya habíamos comprobado al estudiar en un trabajo anterior las estampillas sobre terra sigillata hispánica de Tricio, o como puede verificarse igualmente si se repasa el catálogo de marcas sobre material de construcción de la Meseta elaborado por T. Mañanes. ${ }^{101}$ La única excepción reseñable son los alfareros de Segobriga, pues entre los productores de tegulae de la ciudad se cuentan tres personajes con nombre vernáculo.

Por lo que respecta a las formas cerámicas, hay un ejemplo sobre dolium, otro sobre cerámica engobada, un pequeño grupo de cinco personajes en el caso de la terra sigillata producida en Tricio -muy minoritario si tenemos en cuenta que en este amplio complejo artesanal se atestiguan más de trescientos cincuenta productores-y otra corta serie de sellos en material de construcción (ladrillos y tegulae). Una parte de los productores están documentados por un único o por un menguado número de improntas que, además, no siempre se han recuperado en excavaciones arqueológicas, así sucede con $E X \cdot O \cdot V A L \cdot R E B$, del que solo se conoce una estampilla sobre un plato de cerámica engobada de Calahorra; por su parte, sobre el hallazgo del epígrafe EX OF PROTI VAC/AIAE, atestiguado en tres estampillas, solo se conoce la calle de Astorga en la que fueron recuperadas, y, en cambio, del sello $L E G$ VII GE $R E B$, aunque sí se conoce el contexto arqueológico, resulta casi irrelevante, dado que el ladrillo sobre el que está impreso se recuperó reutilizado en la necrópolis tardoantigua de Vegazana. De otros productores conocemos más de una impronta y todas ellas se han descubierto en un mismo lugar, así sucede con los dos sellos de $P O$ ' $M P E^{\prime}$ ' - COLISI, ambos hallados en Varea, los dos de TVRII OF, recuperados en El Alba, o los ejemplares de CLOVT, todos ellos procedentes de Aquis Querquennis y, también, todas las improntas de los tres productores de tegulae de Segobriga (Turanus, Retucenus y Antiros), que solo se documentan en esta ciudad. El significativo número de sellos del primero de ellos, del que se conoce una cuarentena de ejemplares, y el hecho de que se atestigüen varios signacula del segundo, inducen a concluir que sus alfares, aunque no se hayan localizado, debían estar emplazados en dicha localidad. ${ }^{102} \mathrm{El}$ ejemplo más interesante a este respecto lo ofrece Matugenus, pues sus sellos provienen de varios yacimientos del valle del Esla, que atestiguan una distribución comarcal de sus productos y, además, en uno de ellos, La Corona/El Pesadero (Manganeses), se ha exhumado el alfar en el que, con toda probabilidad, este productor desarrolló su actividad. ${ }^{103}$ Un caso singular lo representan los alfareros de terra sigillata hispánica, pues la producción triciense estuvo destinada a la exportación y, como consecuencia, esta vajilla se difundió por toda la Península y parte del norte de África. Entre los productores con nombre indígena, el mejor documentado es Cantaber, cuyo alfar se localiza en Arenzana de Abajo y del que se conoce un gran número de estampillas, que se han recuperado en distintos y lejanos lugares: Vareia, Celsa, Arcaya, León, Barcelona, Tarragona, Sagunto, Valencia, Lucentum, Conimbriga, Alcácer do Sal, Beja, Mérida, Italica, Baelo, Sala, Thamusida y Volubilis. ${ }^{104}$

\footnotetext{
101 Mañanes Pérez 1983.

102 Los editores, efectivamente, asumen que son productores locales (Abascal Palazón et alii 2000).

103 Marcos Contreras et alii 2006; Misiego Tejada et alii 2013, 364-366.

104 Sáenz Preciado - Sáenz Preciado 1999, 97.
} 
La escasa documentación con la que contamos para parte de estos productores, algunos de los cuales se conocen gracias a una única estampilla, impide precisar la cronología y fijar en qué periodo concreto del alto Imperio estuvieron activos. ${ }^{105}$ Entre los más precoces están los productores de tejas de Segobriga, pues su labor se desarrolla en el siglo I d.C. e incluso es posible que Turanus estuviese ya activo en época de Augusto, lo que concuerda perfectamente con la completa latinización del corpus epigráfico de esta ciudad en el que, no obstante, hay una importante presencia de la onomástica vernácula. ${ }^{106}$ En el caso del centro alfarero del Najerilla, la costumbre de sellar las cerámicas se inicia con la propia producción de TSH -mediados del siglo I d.C.- pero decae en la segunda mitad del siglo II d.C. ${ }^{107}$

Los textos en estas estampillas son muy breves, reducidos en la mayor parte de los casos a un nombre o nombres personales, casi siempre abreviados y que solo en ocasiones aparecen acompañados de la fórmula ex officina abreviada (por ejemplo: $E X$. $O \cdot V A L \cdot R E B)$. Por lo que respecta a las fórmulas onomásticas, la más sencilla se reduce a un único nombre personal: Turani, Antir(i), Turii, Clout(ius/-i), Reb(urrus/urri), Cantabri y Rebur(r) $i$, abreviado en una parte importante de los casos, sin que sea siempre posible determinar si deben desarrollarse en genitivo o nominativo, aunque cuando el nombre está completo, como Turani o Turii, se emplea el caso genitivo.

Existe un grupo de fórmulas onomásticas más complejas, que incluyen un nomen latino y un cognomen indígena: Pompe(i) Colisi, Val(eri) Reb(urri o -urrini), Valeri Rebur(r)in(i) -quizá el mismo personaje que el anterior, productor de TSH y cerámica engobada-, Titi(i) Sangeni y Titi(i) Aio(nis). En el caso de RETVC $\cdot$ IILOCI son dos nombres indígenas que parecen constituir la denominación de un único personaje, pues el segundo de ellos puede interpretarse como el patronímico del primero o bien como uno de los nombres familiares característicos de la onomástica celtibérica.

En el caso de los sellos de Astorga comparece un nombre griego y otro indígena, ambos en genitivo, y es muy plausible que el primero sea un esclavo del segundo: ex of(ficina) Proti Vacaiae. El otro ejemplo de dependencia lo encontramos en los sellos sobre tegulae de Zamora, en los que Matugenus y un segundo individuo con nombre griego (Cepalio) son esclavos -aunque no se explicite el término servus- de Valerius Taurus. ${ }^{108}$ El sello LEG VII REB, por su parte, recoge el nombre abreviado de un productor dependiente de la legio VII. ${ }^{109}$ Lamentablemente, no se indica cuál es su condición, como tampoco sucede en los sellos de L. Terentius en Herrera de Pisuerga, en los que se recoge el nombre de la legio IV: $L \cdot T E R E N T / L \cdot I I I I \cdot M A ;{ }^{110}$ más explícito es un grafito ante cocturam que imita la forma de un sello sobre una tegula de Rosinos de Vidriales, pues el personaje que en él aparece sí señala que es un soldado: Rufus mil(es) l(egionis) X G(eminae) f(ecit). ${ }^{111}$

105 El uso de sellos inscritos sobre cerámica es especialmente característico de este periodo, mientras que desciende sensiblemente en época tardoantigua. En este segundo momento puede destacarse la existencia de una inscripción realizada a molde sobre un cuenco de terra sigillata hispánica tardía recuperado en La Horca (Pantoja, Toledo), en la que se lee $A W A B T E$ / CL, habiéndose interpretado el primero de los términos como el popular nombre local: Ambata (Abásolo - Gutiérrez 2010, 409-410); agradecemos a Fernando Pérez Rodríguez-Aragón la información sobre esta pieza.

106 Sobre este aspecto: Abascal Palazón 2007; la epigrafía de la ciudad está editada en Abascal Palazón et alii 2011.

107 Mezquíriz Irujo 1985, 119.

108 Expuesto en detalle en Simón Cornago e.p.

109 Sobre las marcas militares, véase Morillo - Salido 2013.

110 García y Bellido 1960 (=AE 1960, 210); Pérez González 1989, 202-212.

111 Martín Valls et alii 2002, $\mathrm{n}^{\circ} 14$. 
La parquedad de los textos, a diferencia de lo que sucede en otras producciones romanas, como pueden ser los sellos empleados por la industria latericia urbana o las estampillas de la terra sigillata de Aretium, hace muy difícil determinar la condición jurídica y social de los personajes que aparecen mencionados en las estampillas y determinar de quién se trata realmente, es decir, qué papel desempeñaron en el proceso productivo, si eran los trabajadores manuales, los officinatores, los negotiatores al cargo de la distribución o los propietarios de las figlinae, sin excluir otras opciones. En los sellos de Hispania Citerior predominan los epígrafes escuetos, en los que casi únicamente se recoge una denominación personal a la que puede añadirse una fórmula recurrente como ex officina, frecuentísima, por ejemplo, en la TSH de Tricio. ${ }^{112} \mathrm{En}$ el catálogo que hemos elaborado los textos más sencillos son aquéllos que recogen un único nombre: Turanus, Antirus, Turius, Cloutius, Reburrus, Cantaber y Atto. Estos individuos, cuya denominación se reduce a un único nombre personal, pueden ser esclavos, pero dado que en estos casos se trata de antropónimos indígenas no puede excluirse que sean peregrini. ${ }^{113}$ En ningún sello del catálogo se indica la filiación, algo infrecuente en el conjunto de las estampillas, la única posible excepción es Retucenus Eloci; tampoco aparecen términos como servus o libertus, pero hemos visto cómo es plausible que Matugenus y Protus sean esclavos, pues aparecen como dependientes de un segundo personaje: Valerius Taurus y Vacaia, respectivamente. Por último, hay un grupo de fórmulas onomásticas compuestas por un nomen latino y como cognomen un idiónimo indígena: Pompeius Colis(i)us, Valerius Reburrus, Valerius Reburrinus y Titus Aio; en estos casos es evidente que se trata de individuos libres, presumiblemente de origen local a juzgar por la adscripción lingüística de los cognomina y que, con toda probabilidad, al lucir también nomen gentile, poseían algún estatuto jurídico privilegiado, fuese la ciudadanía romana o el derecho latino.

Los sellos sobre cerámica pueden ser analizados desde diferentes perspectivas y con distintos fines. En este trabajo hemos privilegiado la clasificación lingüística de los antropónimos que en ellos aparecen, recopilando aquellos que pueden clasificarse como indígenas. La profunda latinización de Hispania supone que solo en el interior de la provincia se documenten sellos con nombres vernáculos y que sean una minoría frente a los latinos. El planteamiento propuesto, ya que aceptamos que la onomástica vernácula es exclusiva de los individuos de origen local, permite certificar la participación de los indígenas en las producciones cerámicas provinciales, una parte de las cuales son de clara inspiración romana, como el material latericio de construcción o la terra sigillata. Los sellos ofrecen pues información de gran interés para conocer a los productores y ceramistas de la Hispania Citerior, aunque con excepción de aquéllos que aparecen en las ánforas no han recibido una atención específica. En este trabajo se han analizado desde el punto de vista de la clasificación lingüística de los antropónimos que aparecen en estas marcas, que revela la preponderancia de la onomástica latina, pero también la existencia de un pequeño grupo de nombres vernáculos, propios de la Hispania indoeuropea, y que atestiguan la participación de individuos de origen local en producciones como la terra sigillata o las tegulae.

112 Mayet 1984, 113-114.

113 Sobre la dificultad de interpretar este tipo de textos, en relación a la producción anfórica de la tarraconense: Revilla Calvo 2007; Olesti Vila - Carreras Monfort 2015. Hay que reseñar que se conocen esclavos con nombre indígena, véase el elenco recopilado por Mangas Manjarrés 1971, 55. 


\section{Referencias bibliográficas}

Abascal Palazón, J. M.

(1984): "Los cognomina de parentesco de la península Ibérica. A propósito del influjo romanizador en la onomástica", Lucentum 3, 219-259 (http://dx.doi.org/10.14198/LVCENTVM1984.3.11).

(1994): Los nombres personales en las inscripciones latinas de Hispania (=Antigüedad y cristianismo. Anejos 2), Murcia.

(2007): "Indigenismo y promoción personal en las ciudades antiguas de la Meseta sur", [en] G. Carrasco (coord.), Los pueblos prerromanos en Castilla-La Mancha (=Humanidades 92), Cuenca, 285-305.

Abascal Palazón, J. M. - Alföldy, G. - Cebrián, R. (2011): Segóbriga V. Inscripciones romanas (1986-2010), (=Real Academia de la Historia. Bibliotheca Archaeologica Hispana 38), Madrid.

Abascal Palazón, J. M. - Cebrián, R. - Riquelme, T. (2000): “Retucenos Elocum, Turanus, Antirus y la producción de tegulae en Segobriga", Anales de Prehistoria y Arqueología de la Universidad de Murcia 16, 187-197.

Abásolo, J. A. - García Rozas, R.

(1999): "Sellos y marcas sobre tejas y ladrillos del Museo de Zamora (España)", [en] XI Congresso internazionale di epigrafia greca e latina. Preatti, Roma, 311-317.

(2006): "La romanización de la provincia de Zamora a la luz de sus hallazgos monetarios", [en] Actas del II Congreso de Historia de Zamora, Zamora, 143-168.

Abásolo, J. A. - Gutiérrez, J. (2010): "Rareza o fortuna. Sobre ciertas piezas originales de Terra Sigillata Hispánica Tardía procedentes de La Olmeda", Publicaciones de la Institución Tello Téllez de Meneses 81, 405-413.

Aguarod Otal, C.

(1984): “Avance al estudio de un posible alfar romano en Tarazona: II. Las cerámicas engobadas, no decoradas", Turiaso 5, 29-105.

(1991): Cerámica romana importada de cocina en la Tarraconense, Zaragoza.

Albertos Firmat, M. L. (1966): La onomástica personal primitiva de Hispania. Tarraconense y Bética (=Theses et studia philologica Salmanticensia 13), Salamanca.

Amaré Tafalla, M. T. - Bona López, I. J. - Borque Ramón, J. J. (1983): “Avance al estudio de un posible alfar romano en Tarazona: I. las lucernas", Turiaso 4, 93-110.

Bartolomé Abraira, R. (2015): "Marcas de alfarero sobre cerámica común romana de engobe rojo de producción lucense", Férvedes 8, 351-360.

Beltrán Lloris, F. (2004): "Epigrafía de los niveles 2, 3 y del hypocaustum”, [en] M. Beltrán Lloris - J. Á. Paz Peralta (coords.), Las aguas sagradas del Municipium Turiaso (=Caesaraugusta 76), Zaragoza, 254-258.

Beltrán Lloris, $\mathrm{M}$.

(1984): “Ludus calagurritanus: relaciones entre el municipium Calagurris Iulia y la colonia Victrix Iulia Celsa", [en] Calahorra. Bimilenario de su fundación. Actas del I Symposium de historia de Calahorra, Madrid, 129-138.

(1990): Guía de la cerámica romana, Zaragoza, 1990.

(2003): “Los morteros 'bilingües' del valle del Ebro", Palaeohispanica 3, 59-71.

Bernal, D. - Juan Tovar, L. C. - Bustamante-Álvarez, M. - Díaz, J. J. - Sáez, A. M. (eds.), (2013): Hornos, talleres y focos de producción alfarera en Hispania (=Monografías Ex Officina Hispana 1), Cádiz. 
Bernal, D. - Ribera, A. (eds.), (2008): Cerámicas hispanorromanas: un estado de la cuestión, Cádiz.

Blanco García, J. F. (2017): “Cerámica común romana altoimperial de cocina y mesa, de fabricación local, en la Meseta”, [en] Fernández Ochoa - Morillo - Zarzalejos (eds.), 2017, 143-236.

Blanco García, J. F. - Juan Tovar, L. C. (1996): “Acerca de M.C.R. y otros alfareros hispánicos: marcas y grafitos en terra sigillata hispánica de Cauca (Coca, Segovia)”, Boletín de la Asociación Española de Amigos de la Arqueología 36, 147-155.

Boube, J. (1965): La terra sigillata hispanique en Maurétanie Tingitane 1. Les marques de potiers (=Études et Travaux d'Archaeologie Marocaine 1), Rabat.

Cebrián, R. (2010): "La producción latericia en Segobriga. Nuevos hallazgos (2002-2009)", Lucentum 28, 169-182 (http://dx.doi.org/10.14198/LVCENTVM2009.28.10).

Coixão, A. N. S. - Encarnação, J. d' (2001): “Epigrafía rupestre en Numão”, [en] Saxa Scripta. Actas do III Simposio Ibero-Itálico de Epigrafía Rupestre (=Colecção Ser e Estar 6), Viseu, 199-208.

Díaz Ariño, B. (2008): Epigrafía latina republicana de Hispania (=Universitat de Barcelona. Col·lecció Instrumenta 26), Barcelona (=ELRH).

Espinosa Ruiz, U.

(1986): Epigrafia romana de La Rioja (=Biblioteca de temas Riojanos 62), Logroño $(=E R R)$.

(1994): “Actividades económicas", [en] J. A. Sesma (coord.), Historia de la ciudad de Logroño 1. Antigüedad, Logroño, 179-189.

Espinosa Ruiz, U. - Castillo Pascual, M. J. (1995-1997): “Novedades epigráficas en el medio Ebro (La Rioja)", Lucentum 14-16, 101-112 (http://dx.doi.org/10.14198/LVCENTVM1995-1997.14-16.06).

Fernández Ochoa, C. - Morillo, Á. - Zarzalejos, M. (eds.), (2017): Manual de cerámica romana III. Cerámicas romanas de época altoimperial III: cerámica común de mesa, cocina y almacenaje. Imitaciones hispanas de series romanas. Otras producciones, Madrid.

Forier, S. (2001): "Les anthroponymes formés sur les noms d'animaux en Gaule Narbonnaise et dans les provinces alpines", [en] M. Dondin-Payre - M.-T. Raepsaet-Charlier (eds.), Noms, identités culturelles et romanisation sous le Haut-Empire, Bruxelles, 473-535.

Garabito Gómez, T. (1978): Los alfares romanos riojanos. Producción y comercialización (=Biblioteca Praehistorica Hispana 16), Madrid.

García Alonso, J. L. (2003): La Península Ibérica en la Geografía de Claudio Ptolomeo (=Anejos de Veleia. Series Minor 19), Vitoria.

García Marcos, V. (1990): "Marcas de alfarero en sigillata hispánica halladas en la ciudad de León”, Tierras de León 30, 89-114.

García y Bellido, A. (1960): “L. Terentius, figlinarius en Hispania de la Legión IIII Macedónica", Latomus 44, 374-382.

Gómez Moreno, M. (1925): Catálogo monumental de España. Provincia de Léon, Madrid.

González Blanco, A. - Fernández Matallana, F. - Gallardo Carrillo, J. - Celdrán Iniesta, A. - Molina Gómez, J. A. - Nicolás Pérez, E. - Cinca Martínez, J. L. - Imbernón Perez, C. (1996): "El Alfar de 'La Maja'. Dimensiones insospechadas. Campaña de julio de 1995”, Estrato 7, 49-64.

Gorrochategui Churruca, J. (2011): "Interferencias lingüísticas en el material epigráfico hispano-celta”, [en] E. R. Luján - J. L. García Alonso (eds.), A Greek Man in the Iberian Street. Papers in Linguistics and Epigraphy in Honour of Javier de Hoz (=Innsbrucker Beiträge zur Sprachwissenschaft 140), Innsbruck, 201-216. 
Gorrochategui Churruca, J. - Navarro Caballero, M. - Vallejo Ruiz, J. M. (2007): "Reflexiones sobre la historia social del valle del Duero: las denominaciones personales", [en] Navarro Caballero - Palao Vicente (coords.), 2007, 287-339.

Hartley, B. R. - Dickinson, B. M. (2008-2012): Names on terra sigillata. An Index of makers' stamps \& signatures on Gallo-Roman terra sigillata (Samian ware), (=BICS Suppl. 102106), London.

Jimeno, A. (1980): Epigrafía romana de la provincia de Soria (=Temas Sorianos 2), Soria $(=E R P S)$.

Laguerre, G. (1975): Inscriptions antiques de Nice-Cimiez (Cemenelum, Ager Cemenelensis), Paris.

Le Roux, P. (1999): "Briques et tuiles militaires dans la Péninsule Ibérique: problèmes de production et de difussion", [en] El ladrillo y sus derivados en la época romana (=Monografías de Arquitectura Romana 4), Madrid, 111-123.

Liz Guiral, J. - Amaré Tafalla, M. T. (1993): Necrópolis tardorromana del campus de Vegazana, León.

Lorenzo Morán, J. F. - Martín Arija, A. M. - Salvador Velasco, M. - Viñé Escartín, A. I. Iglesias del Castillo, L. I. (1996): “"El Alba' (Villalazán): un importante yacimiento romano en la provincia de Zamora", Numantia 6, 61-79.

Lorrio Alvarado, A. J. - Pérez Blasco, M. F. (2015): "La inscripción latina pintada sobre cerámica de El Castellar (Crevillent, Alicante)", Lucentum 34, 311-321 (http://dx.doi. org/10.14198/LVCENTVM2015.34.14).

Luezas Pascual, R. A.

(1998): "Sellos de alfarero sobre dolia de la Península Ibérica", Caesaraugusta 74, 207 233.

(2002): Cerámica común romana en La Rioja (=Instituto de Estudios Riojanos. Historia 14), Logroño.

Luján, E. (2016): "Sobre los nombres de las unidades familiares indígenas en la Hispania Antigua (1. a parte)", Veleia 33, 227-258 (http://dx.doi.org/10.1387/veleia.1697).

Mangas Manjarrés, J. (1971): Esclavos y libertos en la España romana (=Acta Salmanticensia. Filosofía y Letras 62), Salamanca.

Mañanes Pérez, T.

(1983): "Marcas de alfarero en materiales de construcción en la Meseta Norte", [en] T. Mañanes, Arqueología vallisoletana II. Torozos, Pisuerga y Cerrato, Valladolid. (2000): Inscripciones latinas de Astorga (=Historia y Sociedad 84), Valladolid (=ILAs).

Marcos Contreras, G. J. - Sandoval Rodríguez, A. N. - Carbajo Martín, M. A. - Sanz García, F. J. - Misiego Tejeda, J. C. (2006): "Producción y distribución de materiales de construcción en época romana: el taller de Manganeses de la Polvorosa, Zamora", [en] Segundo Congreso de Historia de Zamora, Zamora, 257-276.

Martín Valls, R. - Delibes de Castro, G. (1979): "Hallazgos arqueológicos en la provincia de Zamora (VI)”, Boletín del Seminario de Arte y Arqueología 45, 125-147.

Martín Valls, R. - Romero Carnicero, V. - Carretero Vaquero, S. (2002): "Marcas militares en material de construcción de Petauonium", [en] Á. Morillo (ed.), Arqueología militar romana en Hispania (=Anejos de Gladius 5), Madrid, 137-154.

Mayet, F. (1984): Les céramiques sigillées hispaniques (=Collection de la Maison des Pays Ibériques 21), Paris.

Mezquíriz Irujo, M. Á. (1985): "Terra Sigillata Ispanica", [en] Enciclopedia del arte antica: classica e orientale. Atlante ii, Roma, 99-174. 
(1993-1994): "La villa de las Musas (Arellano-Navarra): estudio previo", Trabajos de Arqueología Navarra 11, 55-100.

(2003): La villa romana de Arellano, Pamplona.

Mínguez Morales, J. A.

(2008a): “Gaius Valerius Verdullus y la fabricación de paredes finas con decoración a molde en el valle medio del Ebro. Veinte años después", [en] SFECAG. Actes du congrès de L'Escala-Empúries, Marseille, 181-194.

(2008b): "Las producciones de paredes finas del valle medio del Ebro (España)", Rei Cretariae Romanae Fautorum Acta 41, 429-436.

Misiego Tejada, J. C. et alii (2013): Las excavaciones arqueológicas en el yacimiento de 'La Corona/El Pesadero' en Manganeses de la Polvorosa. La Edad del Hierro y la época romana en el norte de la provincia de Zamora (=Arqueología en Castilla y León 19), Valladolid.

Morais, R. - Fernández, A. - Sousa, M. J. (eds.), (2014): As produçoes cerâmicas de imitação na Hispania (=Monografías Ex Officina Hispana 2), Porto.

Morillo, Á. - Salido, J. (2013): "Marcas militares sobre producciones latericias en Hispania. Nuevas consideraciones sobre su origen y difusión", Gerión 31, 287-329 (http://dx.doi. org/10.5209/rev_GERI.2013.v31.43623).

Navarro Caballero, M. - Gorrochategui Churruca, J. - Vallejo Ruiz, J. M. (2011): "L'onomastique des Celtibères", [en] M. Dondin-Payre (éd.), Les noms de personnes dans l'Empire romain (=Scripta Antiqua 36), Bordeaux, 89-175.

Navarro Caballero, M. - Palao Vicente, J. J. (coords.), (2007): Villes et territoires dans le bassin du Douro à l'époque romaine (=Ausonius Éditions. Études 17), Bordeaux.

Núñez, S. - Curchin L. A. (2007): “Corpus de ciudades romanas”, [en] Navarro Caballero Palao Vicente (coords.), 2007, 429-612.

Olesti Vila, O. - Carreras Monfort, C. (2015): "De servus a propietario agrícola: el esclavo en el mundo de la producción anfórica en el Ager Barcinonensis", [en] A. Beltrán - I. Sastre - M. Valdés (dir.), Los espacios de la esclavitud y la dependencia en la Antigüedad. Actes XXV Congres de GIREA. Homenaje a Domingo Plácido, Franche-Comté, 561-587.

Pérez González, C. (1989): Cerámica romana de Herrera de Pisuerga (Palencia, España). La terra sigillata, Santiago de Chile, 1989.

Revilla Calvo, V. (2007): “Onomástica en epigrafía anfórica de la Hispania Tarraconense: algunas consideraciones sobre el significado y métodos de análisis”, [en] M. Mayer-G. Baratta - A. Guzmán (eds.), Provincia Imperii Romanae Inscriptionibus Descripta. Acta XIII Congressus Internationalis Epigraphiae Graecae et Latinae (Barcelona, 3-8 Septembris 2002), Barcelona, vol. 2, 1183-1192.

Roca Roumens, M. - Principal, J. (2007): Les imitacions de vaixella fina importada a la Hispania Citerior (segles I $a C-d C$ ), (=Institut Català d'Arqueologia Clàssica. Sèrie Documenta 6), Tarragona, 235-257.

Rodríguez Colmenero, A. (2006): "Epigrafía, arte y materiales de construcción. Testimonios”, [en] Excavaciones arqueológicas en Aquis Querquennis (=Anejos de Larouco 4), Lugo, 141-180.

Romero Carnicero, M. V. (1985): Numancia I. La terra sigillata (=Excavaciones arqueológicas en España 146), Madrid.

Romero Carnicero, M. V. - Crespo Mancho, M. J. - Lión Bustillo, C. (2016): “De nuevo sobre M.C.R., Asiaticus y Maternus", Boletín del Seminario de Arte y Arqueología 72, 155-193.

Sáenz Preciado, M. P. (1994): “Marcas y grafitos del centro alfarero de La Cerezada (Arenzana de Arriba, La Rioja)”, Berceo 127, 79-113. 
Sáenz Preciado, M. P. - Sáenz Preciado, C. (1999): "Estado de la cuestión de los alfares riojanos: la terra sigillata hispánica altoimperial”, [en] M. Roca Roumens - M. I. Fernández García (eds.), Terra sigillata hispánica. Centros de fabricación y producciones altoimperiales, Málaga, 61-136.

Salido Domínguez, J. (2017): "Los dolia en Hispania: caracterización, funcionalidad y tipología", [en] Fernández Ochoa - Morillo - Zarzalejos (eds.), 2017, 237-309.

Salvat Golobardes, E. (2005): "La tècnica de l'estampillat a l'epigrafia ibèrica i celtibèrica", Sylloge Epigraphica Barcinonensis 5, 149-172.

Schmidt, K. H. (1957): "Die Komposition in gallischen Personennamen”, Zeitschrift für Celtische Philologie 26/3, 161-301.

Sevillano Carvajal, V. (1967): "Tegulas romanas de la provincia de Zamora”, Archivo Español de Arqueología 40, 151-154.

Simón Cornago, I.

(2013a): Los soportes de la epigrafía paleohispánica. Inscripciones sobre piedra, bronce y cerámica, Zaragoza.

(2013b): "El final de las escrituras paleohispánicas", Palaeohispanica 13, 167-186.

(2016a): "Los alfareros de terra sigillata hispánica con nombre indígena”, Palaeohispanica 16, 95-113.

(2016b): "Los primeros sellos sobre terra sigillata producida en Hispania", Archeologia Classica 77, 613-628.

(e.p.): “Cepalio y Matugenus, productores de tegulae y esclavos de Valerio Tauro", Latomus.

Solin, H. - Salomies, O. (1994): Repertorium nominum gentilium et cognominum Latinorum, Hildesheim-Zürich-New York.

TIR J-30 = Tabula Imperii Romani. Hoja J-30, Valencia, Madrid, 2001.

TIR K-29 = Tabula Imperii Romani. Hoja K-29, Conimbriga, Bracara, Lucus, Asturica, Madrid, 1991.

TIR K-30 = Tabula Imperii Romani. Hoja K-30, Caesaraugusta, Clunia, Madrid, 1993.

Untermann, J.

(1975-1997): Monumenta Linguarum Hispanicarum, Wiesbaden (=MLH I-IV).

(1996): “Onomástica”, [en] F. Beltrán - J. De Hoz - J. Untermann, El tercer bronce de Botorrita (Contrebia Belaisca), Zaragoza, 109-166.

Vallejo Ruiz, J. M.

(2004): Antroponimia indígena de la Lusitania romana (=Anejos de Veleia. Series Minor 23), Vitoria.

(2005): “La composición en la antroponimia antigua de la Península Ibérica", Palaeohispanica $5,99-134$.

(2013): "El concepto de área onomástica: el caso de los astures", Studia Historica. Historia Antigua 31, 89-113.

(2016): Banco de Datos Hesperia de Lenguas Paleohispánicas III. Onomástica Paleohispánica I. Antroponimia y teonimia 1. Testimonios epigráficos latinos, celtibéricos y lusitanos, y referencias literarias, https://web-argitalpena.adm.ehu.es/listaproductos. asp?IdProducts=UHPDF163064.

Villar, F. - Jordán Cólera, C. (2002): “Apéndice I. Morfología derivativa del sufijo -ko-”, [en] F. Villar-M. A. Díaz - M. M. Medrano - C. Jordán, El IV bronce de Botorrita (Contrebia Belaisca): arqueología y lingüística (=Acta Salmanticensia. Estudios filológicos 286), Salamanca, 155-190. 